\title{
(2) OPEN ACCESS \\ Necessity is the mother of invention: how the COVID-19 pandemic could change medical student placements for the better
}

\author{
Rebecca C Stout (1) , ${ }^{1,2}$ Sophie Roberts, ${ }^{1}$ Hector Maxwell-Scott, ${ }^{1}$ Philip Gothard ${ }^{1,2}$
}

${ }^{1}$ Infectious and tropical diseases, Hospital for Tropical Diseases, University College London Hospitals, London, UK

FFaculty of Infectious and Tropical Diseases, London School of Hygiene \& Tropical Medicine, London, UK

Correspondence to Dr Rebecca C Stout, Hospital for Tropical diseases, University College Hospital, London NW1 2BU, UK;

rebecca.stout1@nhs.net

Received 7 January 2021 Accepted 30 January 2021 Published Online First 16 February 2021

\section{ABSTRACT}

COVID-19 led to the widespread withdrawal of faceto-face hospital-based clinical placements, with many medical schools switching to online learning. This precipitated concern about potential negative impact on clinical and interprofessional skill acquisition. To overcome this problem, we piloted a 12-week COVID-19 safe face-to-face clinical placement for 16 medical students at the Hospital for Tropical Diseases, London, during the first wave of the COVID-19 pandemic. COVID-19 infection control measures necessitated that students remained in 'social bubbles' for placement duration. This facilitated an apprenticeship-style teaching approach, integrating students into the clinical team for placement duration. Team-based learning was adopted to develop and deliver content. Teaching comprised weekly seminars, experiential ward-based attachments and participation in quality improvement and research projects. The taught content was evaluated through qualitative feedback, reflective practice, and pre-apprenticeship and post-apprenticeship confidence questionnaires across 17 domains. Students' confidence improved in 14 of 17 domains $(p<0.05)$. Reflective practice indicated that students valued the apprenticeship model, preferring the longer clinical attachment to existent shorter, fragmented clinical placements. Students described improved critical thinking, group cohesion, teamwork, self-confidence, self-worth and communication skills. This article describes a framework for the safe and effective delivery of a longer face-to-face apprenticeship-based clinical placement during an infectious disease pandemic. Longer apprenticeship-style attachments have hidden benefits to general professional training, which should be explored by medical schools both during the COVID-19 pandemic and, possibly, for any future clinical placements.

\section{INTRODUCTION}

The first wave of the COVID-19 pandemic caused significant disruption to medical schools and the education of undergraduates around the world. ${ }^{1}$ As COVID-19 cases rose, most face-to-face clinical placements were terminated, replaced with online, remote teaching. ${ }^{1-3}$ Precipitants included redirecting staff towards patient care, ${ }^{3}$ keeping students safe from the exposure to SARS-CoV- $2^{1}$ and, in the USA, trying to save personal protective equipment for staff who needed it most. ${ }^{4}$ Consequently, medical schools were charged with the responsibility of continued curriculum delivery (which continued to be assessed by the Objective Structured Clinical
Examination $(\mathrm{OSCE})^{5}$ ) while maintaining appropriate infection control practices. ${ }^{6}$

To achieve this, many universities moved their education online, ${ }^{7-10}$ which came with advantages such as flexibility and improved access to learning resources. ${ }^{9}$ However, social cognitive learning theory indicates that learning is enhanced through environmental interactions. ${ }^{11}$ Therefore, it could be argued that face-to-face clinical learning, with its dynamic interaction between students, patients and doctors, fosters essential clinical skills and professional behaviours ${ }^{9}$ which cannot be generated by online, remote learning. ${ }^{12}$ Furthermore, Chandrashekar and Mohan ${ }^{13}$ argue that teamwork is fundamental to working within healthcare and should therefore be an integral aspect of the UK undergraduate curriculum. Removing face-to-face clinical rotations from the medical school teaching programme, to limit COVID-19 exposure risk, potentially threatened development of these key teamwork skills.

Arguably, before the pandemic, clinical placements required review. For example, clinical year medical students at the University College London (UCL) rotated between departments monthly. Rotations were often split between more than one department. Delivery format included scheduled sessions in different settings, namely wards, clinics or tutorial sessions. Students frequently moved between cohorts and rarely had the same preceptor for an entire clinical block. This model is mirrored throughout many UK medical schools and has been criticised for limiting clinical exposure, being impersonal, failing to generate clinical role models ${ }^{14}$ and potentially detracting from, rather than engendering, teamwork. To overcome this, we invited $16 \mathrm{UCL}$ medical students, who had volunteered to work in the hospital during the COVID-19 pandemic, to undertake a 12-week-long 'COVID-19 apprenticeship' in accordance with General Medical Council ${ }^{15}$ and Medical Schools Council $^{16}$ guidance. This apprenticeship revolutionised clinical teaching delivery during the first wave of the pandemic.

COVID-19 infection control measures necessitated smaller and more stable social bubbles, ${ }^{17}$ indirectly driving longer period, continuous, smallgroup learning. To further stimulate team cohesion, we delivered teaching through team-based learning (TBL) integrated as weekly seminars around our core COVID-19 themes. Unexpectedly, we found students preferred this method of delivery to their normal short-term, fragmented clinical placements. 


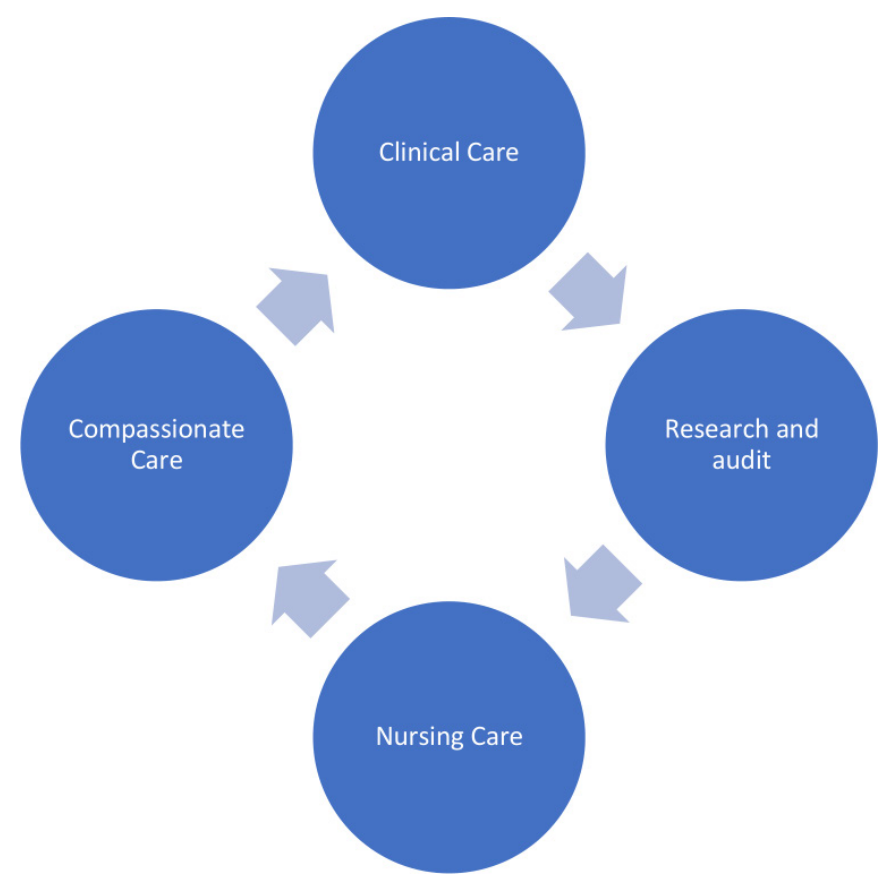

Figure 1 Rotations shows the four three-week teaching blocks that medical students rotated through in their teams throughout the placement: clinical care, research and audit, nursing care and compassionate care.

Feedback described improved teamwork, pastoral care, transferable skills, a feeling of 'belonging' and resultant greater placement enjoyment. Consequently, we propose that COVID-19 does not necessitate complete withdrawal of face-to-face clinical teaching and can instead be used as an opportunity to engender longer, apprenticeship-based placements. We suggest this model could be adopted by medical schools both in an epidemic setting and possible for any future clinical placement. As an education community, we now have an opportunity to learn from teaching delivered during the first peak of the COVID-19 pandemic and a responsibility to improve and modify teaching programmes with a view to shaping well-rounded clinicians of the future. ${ }^{18} 19$

\section{METHODS}

\section{Student recruitment}

We recruited 16 medical students from UCL medical school in 2020 in accordance with government ${ }^{20}$ and Medical Schools Council guidance $^{16}$ for medical student volunteering. Fourteen were in the penultimate (fifth) year of study, one in the final year and one in the fourth year.

\section{Organisation and practical experience}

The 16 students were split into four teams of four students. In these teams, every three weeks for a total of 12 weeks (figure 1), they rotated through four clearly defined teaching blocks: clinical care, research and audit, nursing care and pastoral care, each with its own set of learning objectives. By placing them in the same team for the whole three months, we hoped they would foster friendship and develop natural support groups, as well as ensure they remained in the same social bubble.

During the 'clinical care' block, students were attached to the Infectious Diseases team. They attended daily ward rounds, examined patients, documented in notes and performed practical procedures such as phlebotomy and cannulation. In the 'research and audit' block, they were given autonomy to choose

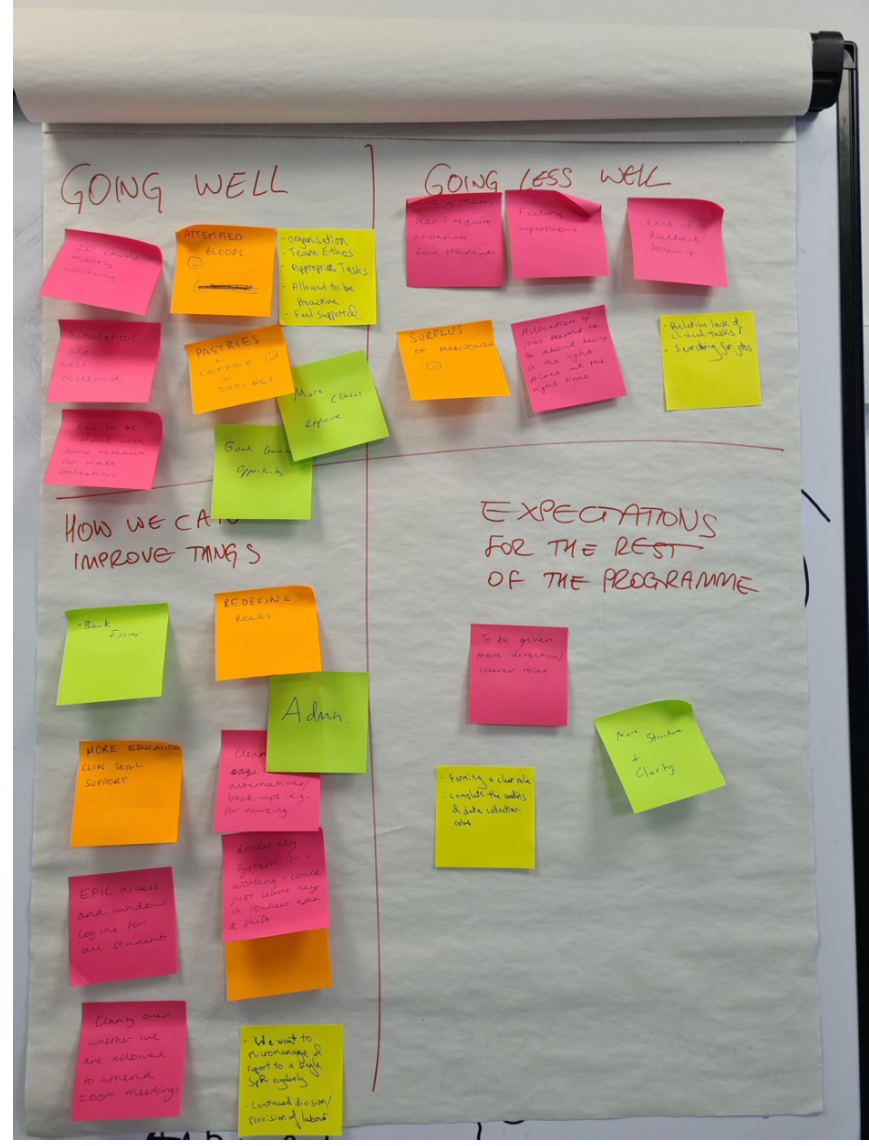

Figure 2 Weekly post-it note feedback shows one of the feedback mechanisms we implemented on a weekly basis. Students, in their teams, were asked to write on post-it notes what was 'going well', 'going less well', 'how we can improve things' and 'expectations for the rest of the programme'. They put the post-it notes onto a communal feedback board (shown), and we discussed issues raised as a whole class.

a project of relevance to the overall COVID-19 response. For the 'nursing care' block, they were paired up with a nurse or nursing assistant to help with patient care. For the 'compassionate care' block, their role was to support the ward staff and to work with the palliative care team caring for dying patients.

\section{Structured teaching delivered}

The group attended weekly two-hour seminars using $\mathrm{TBL}^{21} 22$ to explore various concepts around COVID-19, infectious diseases and public health. This format was selected with the aim of providing a feedback-rich learning and developing the interpersonal and teamworking skills of the learners. ${ }^{22}{ }^{23}$ The seminars began with a 15 -min feedback session, which was an opportunity to troubleshoot any issues. This was done through the use of post-it notes, which teams wrote on and were displayed on a board under the headings 'going well', 'going less well', 'how could we improve things?' and 'expectations for the rest of the programme' (figure 2). Positive feedback was celebrated, and suggested improvements were discussed with solutions sought.

\section{Holistic care}

Students attended weekly feedback meetings in two groups of eight. These were facilitated by the apprenticeship lead (PG), who is an infectious diseases consultant with expertise in medical 
Table 1 Pre and post-apprenticeship questionnaire: "On a scale of 1 (not at all confident) to 5 (extremely confident) how confident are you in..."

\begin{tabular}{|c|c|c|c|}
\hline Domain & $\begin{array}{l}\text { Pre-course } \\
\text { mean score }\end{array}$ & $\begin{array}{l}\text { Post-course } \\
\text { mean score }\end{array}$ & $P$ value \\
\hline $\begin{array}{l}\text { Taking a history from and examining a } \\
\text { patient by yourself }\end{array}$ & 3.53 & 3.53 & 1 \\
\hline $\begin{array}{l}\text { Identifying a patient with signs and } \\
\text { symptoms of COVID-19 }\end{array}$ & 3.13 & 4.40 & $<0.01$ \\
\hline $\begin{array}{l}\text { Investigating a patient who potentially } \\
\text { has COVID-19 }\end{array}$ & 2.67 & 3.87 & $<0.01$ \\
\hline Performing venepuncture & 3.13 & 3.8 & 0.04 \\
\hline Performing cannulation & 2.6 & 3.07 & 0.01 \\
\hline Writing patient discharge summaries & 1.67 & 2.8 & $<0.01$ \\
\hline $\begin{array}{l}\text { Managing patients with complex medical } \\
\text { needs as well as SARS-CoV-2 }\end{array}$ & 1.67 & 2.8 & $<0.01$ \\
\hline Identifying a clinically deteriorating patient & 2.93 & 3.73 & $<0.01$ \\
\hline $\begin{array}{l}\text { Asking for help or advice from senior } \\
\text { colleagues }\end{array}$ & 3.73 & 4.27 & 0.1 \\
\hline $\begin{array}{l}\text { Communicating with members of the } \\
\text { multidisciplinary team }\end{array}$ & 2.6 & 3.4 & 0.03 \\
\hline $\begin{array}{l}\text { Describing methods of infection control for } \\
\text { communicable diseases }\end{array}$ & 3.0 & 4.27 & $<0.01$ \\
\hline $\begin{array}{l}\text { Describing the outbreak investigation } \\
\text { process }\end{array}$ & 1.93 & 3.53 & $<0.01$ \\
\hline $\begin{array}{l}\text { Describing symptoms that are commonly } \\
\text { seen in the last stages of life }\end{array}$ & 3.07 & 4.27 & $<0.01$ \\
\hline $\begin{array}{l}\text { Discussing the challenges of vaccine } \\
\text { design }\end{array}$ & 2.07 & 3.4 & $<0.01$ \\
\hline $\begin{array}{l}\text { Describing the difference between } \\
\text { research, audit and quality improvement }\end{array}$ & 2.73 & 3.67 & $<0.01$ \\
\hline $\begin{array}{l}\text { Describing how global politics can impact } \\
\text { disease management }\end{array}$ & 2.6 & 3.87 & $<0.01$ \\
\hline $\begin{array}{l}\text { Voicing your opinion in front of your peers } \\
\text { in a small-group teaching setting }\end{array}$ & 3.6 & 3.87 & 0.26 \\
\hline
\end{tabular}

education. The sessions provided an opportunity to check in on what each student had spent the week doing, share any themes of interest and identify problems so that they could be addressed proactively.

\section{Methods of evaluation}

We used a mixed-methods approach to triangulate data. Students completed a pre-apprenticeship and post-apprenticeship questionnaire to assess whether their confidence improved over the duration of the apprenticeship (see table 1). They also completed free-text evaluation forms at the end of the apprenticeship.

We asked students to 'write a letter to my future self', at the beginning of the apprenticeship. This was put in a time capsule and remained closed for the duration of the placement. On the final day, we opened the time capsule, and students wrote a reflection based on the letter. Each letter was confidential and only read by the student who wrote it. The anonymous reflection was handed in and is used here as a method of qualitative evaluation.

\section{Statistical analysis}

Fifteen of the 16 students completed both a pre-course and a post-course questionnaire in which they were asked to rate their own confidence across 17 clinical domains on a scale from 1 to 5. Pre-course and post-course mean scores were calculated and compared using a paired t-test.

\section{Qualitative analysis}

Qualitative data were thematically analysed. Two investigators (RCS and SR) generated codes through independent open

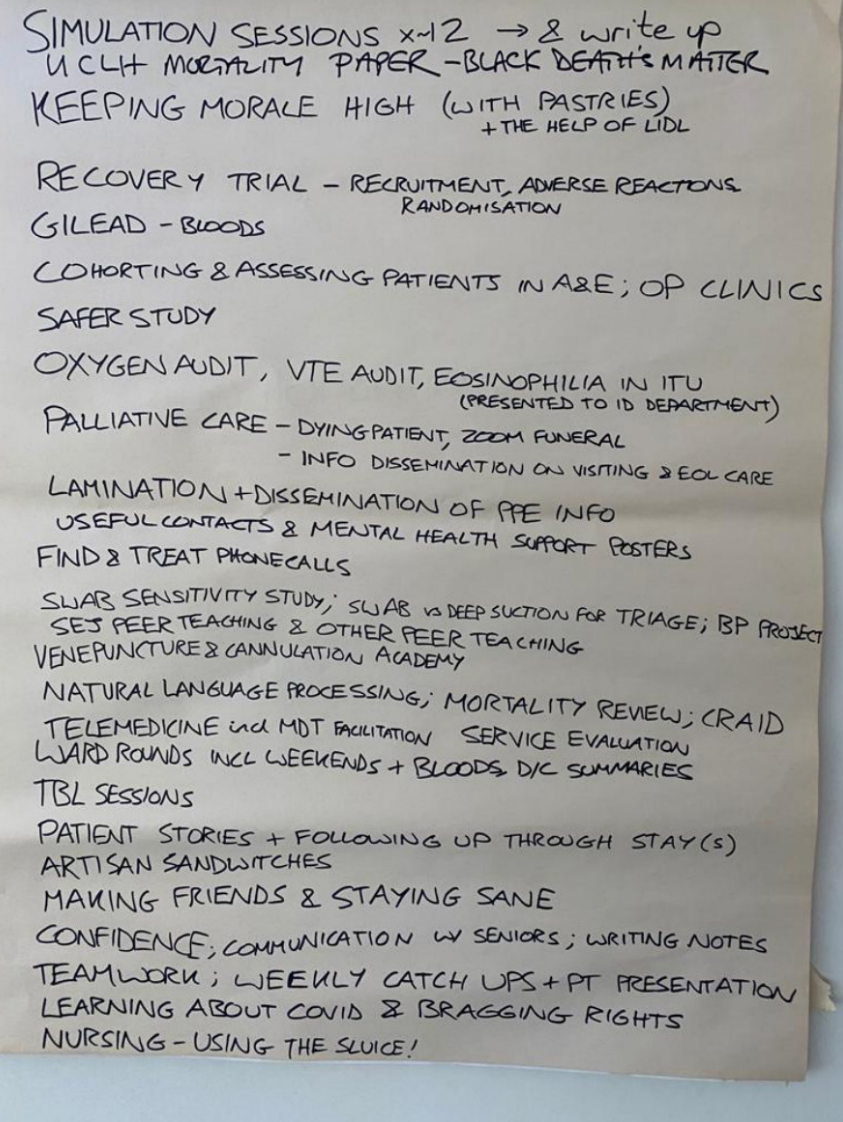

Figure 3 List of projects undertaken by students is a photograph taken of the list of projects students did while they were placed with us. These were projects they recalled contributing to in our final feedback seminar and include teaching projects, clinical experience with patients, local audits, national research and helping set up telemedicine clinics.

coding. Codes were organised into themes. The study team reviewed the final themes to ensure they agreed with them.

\section{Ethical approval}

This study falls under the UCL Research Ethics Committee exemption category 4; therefore, ethical approval was not required.

\section{RESULTS}

\section{Attendance}

Of the 16 students who started the apprenticeship, all but one completed the full 12 weeks. The student who left the apprenticeship continued to attend the TBL sessions. Attendance at TBL was $100 \%$ for every session of the apprenticeship. Fifteen of the 16 students completed the pre-course and postcourse evaluation. Twelve students completed the reflective time capsule exercise.

\section{Projects}

Students took part in a range of projects throughout the placement. A list of these, collected in the final session, can be viewed in figure 3. Projects included running simulation sessions to train staff being moved to new COVID-19 wards,${ }^{24}$ helping in clinical trials, audits on the wards, helping with bloodborne virus testing in the rehoused homeless population, analysing the demographic background of patients dying of COVID-19 and helping to set up a new telemedicine clinic. 


\section{Confidence levels}

In 14 of the 17 domains, there was a significant improvement in students' self-assessed confidence ( $p<0.05$ in all cases), whereas in a further three domains there was a non-significant trend to improvement (table 1).

\section{Clinical, knowledge, teaching and research skills gained}

Students highlighted many skills gained from the apprenticeship, which they described as being transferable and useful for career development. They described improved clinical skills including phlebotomy and cannulation. They also described improved knowledge in topics relevant to COVID-19, but more importantly they described improved critical thinking skills. They valued the opportunity to undertake audit and research, describing skills gained as being invaluable later in their careers. The students described their experience of running a simulation scenario to train doctors and nurses about COVID-19 as both rewarding and a good way of learning about the clinical aspects of the disease:

'I hope to use the deductive skills that I have honed to inform my approach to complex patients.'

\section{The team}

Students described being a part of a team as being key. They enjoyed getting to meet and work with new people and described this as fun. Working collaboratively instead of competitively was highlighted as something which differed from 'normal' medical school placements and as something which would be a useful skill for the future:

'Something you never learn in medical school, despite its key role in being a doctor, is how to work in a team. If anything, in medical school the only skill you foster is how to be competitive with other students. This placement has taught me how to best communicate with other members in a team to efficiently get tasks done.'

They also described being within the same team as helping them to develop their professional skills:

'I believe that working with one team made me feel more competent and I wasn't scared to ask questions', and: 'spending lots of time with one team was great as they get to know you, involve you and help you out on things you're not confident with. This would be an amazing experience for our usual clinical placements'.

\section{Apprenticeship design}

In addition to being part of the same team for the duration of the apprenticeship, having a longer placement of 12 weeks was highlighted as particularly useful, in terms of both integrating into the team and gaining an insight into the workings of a hospital. Having biweekly interaction with team leaders was described as important in keeping students motivated, particularly with ward working and projects such as audits:

'... regular meetings and face to face guidance ... Felt like we were well looked after and were given specific tasks that we could go and do with autonomy, but help was available if needed.'

Weekly teaching in a TBL format was felt to aid learning and was described as giving students the opportunity to think in depth about subjects rather than learning knowledge for multiple-choice exams. It was described as a style of intellectual thinking that will be useful in their future careers.

\section{Personal and professional development}

Reflective practice led students to describe introspective learning, demonstrating how the apprenticeship model aided development of personal and professional attributes essential for a holistic clinical approach. These included improved self-sufficiency, time management, resilience, independence and confidence. Students were also reflective and able to identify areas for improvement, as well as describe improved communication skills with both patients and doctors:

'I feel as if I now have a doctor's sense of self, a doctor's sense of purpose and the person I envision myself becoming.'

\section{Culture}

Students highlighted the department's culture as being positive and described feeling valued, as well as meeting role models as valuable:

'I would like to emulate some of the doctors I came into contact with.'

\section{Fear of COVID-19}

Students were asked whether they had concerns about personal safety in relation to COVID-19. While several students described some concerns at the beginning of the apprenticeship, most commented that as the apprenticeship progressed, and their knowledge of COVID-19 increased, their concerns reduced. None of the students reported symptoms of COVID-19 during the apprenticeship:

'the placement actually made me feel safer ... [I was] less caught up with scary news headlines and more in the real world.'

\section{DISCUSSION}

During the 12-week period, we set out to deliver clinical teaching for a small group of students who would have otherwise been withdrawn from clinical placements with access to online teaching only. Infection control necessitated working within small social bubbles over the 12 -week block. In contrast with the normal short-period, large-group clinical placements, an incidental but essential by-product of extended period, smallgroup learning was that students thrived.

While this longer apprenticeship-style learning model required increased supervision, mentoring and feedback in comparison with the existent strategy, beneficial outcomes included improved teamwork, professional development and clinical skills. This demonstrated that this teaching approach was preferable to the existent short placement model adopted by most UK medical schools.

Studies preceding the COVID-19 pandemic reported limited clinical exposure and bedside teaching within medical school curricula. $^{25}$ Conversely, our approach demonstrates a way of integrating substantial clinical experience into medical student teaching via an extended placement with the same clinical team. Students described how the longer apprenticeship allowed them to integrate into the clinical team, which in turn helped them to develop as professionals. They also reported a positive experience of having regular check-in meetings with the same clinical educator, whose role was to motivate and monitor their progress. This correlates with findings from longitudinal integrated clerkships (LICs), placements that involve a regular and recurrent placement with the same teacher (and therefore with the same cohort of patients) over a period of time. LICs demonstratively 


\section{List of learning points}

- Clinical experience is an essential aspect of medical training and continues to be assessed by the OSCE. This study demonstrates it is possible to teach clinical skills face-to-face within the context of a pandemic.

- Strong teamwork, interprofessional skills and improved selfconfidence derive from extended (12-week-long) placements with a single department/team.

- Longer placements enhance development of transferable skills, which can be used across medical and surgical specialities.

- Improved pastoral care resulted from placing students into formalised teams for the duration of the 12-week period. This infection control by-product helped foster informal 'learner communities' and support groups over enhancing student support experience beyond that experienced during normal medical school placements.

\section{Future research questions}

- Does a longer clinical placement enable increased professional development for medical students?

- How do longer placements impact teamwork and development of interprofessional skills?

- Does a global pandemic always necessitate withdrawal of face-to-face clinical learning for medical students?

- How has withdrawal of clinical placements impacted medical students' clinical competencies?

indicate that inclusion in the clinical team results in richer learning experiences. ${ }^{26}$ Evidence indicates that students benefit from longer periods with the same student cohort and group supervisor with whom they become well acquainted, allowing for the development of individualised learning plans. ${ }^{27} 28$

One criticism of LICs, which are often in communitybased settings, is the potential for students to become socially isolated. ${ }^{29}$ Similarly, this was a concern in our study, as lockdown measures potentially exposed students to feeling isolated. However, paradoxically students described making more new friends and better support groups than during pre-COVID-19 clinical placements. Overall, the longer nature of the apprenticeship, with regular tutor mentorship and coaching, proved to be a positive experience for learners. This by-product can be replicated, pandemic or not.

Workload burden for tutors involved in LICs has been described as higher than that of shorter rotations ${ }^{30}$; we as the lead preceptors (RCS and PG) agree with this. However, subjectively, the reward in supervising the same group of students and seeing them develop as professionals outweighed this limitation.

The students in our study said they enjoyed the TBL format. Despite seminars concentrating on topics relating to COVID-19, at the end of the placement the students described having developed generic critical thinking skills, improving their approach to an array of clinical problems. These professional skills of communication, teamworking and appraisal can be applied to many areas of medicine irrespective of the placement. Finally, the use of TBL helped to foster a positive sense of teamwork between students, which in turn improved their learning experience. ${ }^{31} 32$
In addition to enhanced student learning and pastoral experience, the apprenticeship approach benefited the hospital, as students undertook several tasks in addition to direct patient care. This included audit, contributing to research studies and facilitating staff redeployment training. Students identified resultant professional skills as being essential to their personal development as future clinicians. These outcomes reinforce previously published findings, which demonstrate the value of student involvement in clinical audit, teaching and research. ${ }^{33-36}$ Clinical skills were also developed during daily phlebotomy and cannulation rounds. In addition, students developed strong communication skills, phoning family members and sitting with dying patients. This again benefited the hospital during a time of heightened stress and staff shortages (owing to increased staff sickness), as students helped to ease the pressure on other members of the multidisciplinary team.

The COVID-19 pandemic forced rapid and extreme change to the delivery of undergraduate clinical placements. We used this as an opportunity to innovate clinical teaching delivery. The resultant 12 -week placement was sufficiently long for students to form meaningful relationships with members of the clinical team. Although a long placement in one department carries the risk of limiting students' exposure to one speciality and its cohort of patients, the skills students actually gained transcended clinical knowledge to encompass a host of personal and professional skills.

\section{Twitter Rebecca C Stout @BeckyStout8}

Acknowledgements Thanks to the infectious diseases team at the Hospital for Tropical Diseases and the 16 medical students who volunteered. Thanks to Professor Terence Poulton for his help and to Dr Ali Winstanley, Dr Gavin Johnson and Professor Deborah Gill for supporting the programme and providing some useful references. Thank you to the Hospital for Tropical Diseases Charitable Fund, who supported payment of publication fees.

Contributors RCS and PG both contributed to the planning, design, delivery, reporting, drafting, revision and final approval of the work. RCS and SR analysed qualitative data. SR contributed to the planning and design, and reviewed manuscript with suggestions and final approval of work. HM-S contributed to the design and delivery, analysed the statistics and reviewed manuscript with suggestions and final approval of work.

Funding The authors have not declared a specific grant for this research from any funding agency in the public, commercial or not-for-profit sectors.

\section{Competing interests None declared.}

Patient consent for publication Not required.

Provenance and peer review Not commissioned; internally peer reviewed.

Open access This is an open access article distributed in accordance with the Creative Commons Attribution Non Commercial (CC BY-NC 4.0) license, which permits others to distribute, remix, adapt, build upon this work non-commercially, and license their derivative works on different terms, provided the original work is properly cited, appropriate credit is given, any changes made indicated, and the use is non-commercial. See: http://creativecommons.org/licenses/by-nc/4.0/.

\section{ORCID iD}

Rebecca C Stout http://orcid.org/0000-0002-8431-399X

\section{REFERENCES}

1 Tolsgaard MG, Cleland J, Wilkinson T, et al. How we make choices and sacrifices in medical education during the COVID-19 pandemic. Med Teach 2020;42:741-3.

2 Kinder F, Harvey A. Covid-19: the medical students responding to the pandemic. BMJ 2020;369:m2160.

3 Liang ZC, Ooi SBS, Wang W. Pandemics and their impact on medical training: lessons from Singapore. Acad Med 2020;95:1359-61.

4 Akers A, Blough C, lyer MS. COVID-19 implications on clinical clerkships and the residency application process for medical students. Cureus 2020;12:e7800.

5 McNair R, Griffiths L, Reid K, et al. Medical students developing confidence and patient centredness in diverse clinical settings: a longitudinal survey study. BMC Med Educ 2016;16:176. 
6 Ashokka B, Ong SY, Tay KH, et al. Coordinated responses of academic medical centres to pandemics: sustaining medical education during COVID-19. Med Teach 2020;42:1-10.

7 Sandhu P, de Wolf M. The impact of COVID-19 on the undergraduate medical curriculum. Med Educ Online 2020;25:1764740.

8 Mukhtar K, Javed K, Arooj M, et al. Advantages, limitations and recommendations for online learning during COVID-19 pandemic era. Pak J Med Sci 2020;36:S27-31.

9 Yusoff MSB, Hadie SNH, Mohamad I, et al. Sustainable medical teaching and learning during the COVID-19 pandemic: surviving the new normal. Malays J Med Sci 2020;27:137-42.

10 Thistlethwaite J, Locke R, Buckley S, et al. Global perspectives on Covid-19 from the editorial board. Clin Teach 2020;17:234-7.

11 Nisbet G, Lincoln M, Dunn S. Informal interprofessional learning: an untapped opportunity for learning and change within the workplace. J Interprof Care 2013;27:469-75.

12 Hammond D, Louca C, Leeves L, et al. Undergraduate medical education and Covid-19: engaged but Abstract. Med Educ Online 2020;25:1781379.

13 Chandrashekar A, Mohan J. Preparing for the National health service: the importance of teamwork training in the United Kingdom medical school curriculum. Adv Med Educ Pract 2019;10:679-88.

14 Dornan T, Osler DT. Osler, Flexner, apprenticeship and 'the new medical education'. J $R$ Soc Med 2005;98:91-5.

15 GMC. Letter in: UK medical schools, 2020.

16 Council MS. Statement of expectation medical student volunteers in the NHS: medical schools Council website, 2020. Available: https://www.medschools.ac.uk/media/2641/ updated-volunteering-guidance-020420.pdf

17 Gill D, Whitehead C, Wondimagegn D. Challenges to medical education at a time of physical distancing. Lancet 2020;396:77-9.

18 Roskvist R, Eggleton K, Goodyear-Smith F. Provision of e-learning programmes to replace undergraduate medical students' clinical general practice attachments during COVID-19 stand-down. Educ Prim Care 2020;31:247-254

19 Roberts C. How medical education can help in a COVID-19 crisis. Clin Teach 2020;17:241-3.

20 Bosotti A. UK calls for army of 250k volunteers to support NHS as thousands of retired doctors return. The Express, 2020.

21 Parmelee DX, Michaelsen LK. Twelve tips for doing effective team-based learning (TBL). Med Teach 2010:32:118-22.
22 Parmelee D, Michaelsen LK, Cook S, et al. Team-based learning: a practical guide: AMEE guide No. 65. Med Teach 2012;34:e275-87.

23 Burgess A, Haq I, Bleasel J, et al. Team-based learning (TBL): a community of practice. BMC Med Educ 2019;19:369.

24 Ekert JO, Luchesa Smith A, Ramsey CL, et al. Medical student-led simulation in COVID-19 crisis. Clin Teach 2020. doi:10.1111/tct.13308. [Epub ahead of print: 06 Dec 2020].

25 Jones P, Rai BP. The status of bedside teaching in the United Kingdom: the student perspective. Adv Med Educ Pract 2015;6:421-9.

26 Thistlethwaite JE, Bartle E, Chong AAL, et al. A review of longitudinal community and hospital placements in medical education: BEME guide No. 26. Med Teach 2013;35:e1340-64.

27 Norris TE, Schaad DC, DeWitt D, et al. Longitudinal integrated clerkships for medical students: an innovation adopted by medical schools in Australia, Canada, South Africa, and the United States. Acad Med 2009;84:902-7.

28 Bartlett M, Couper I, Poncelet A, et al. The do's, don'ts and don't knows of establishing a sustainable longitudinal integrated clerkship. Perspect Med Educ 2020;9:5-19.

29 Daly M, Roberts C, Kumar K, et al. Longitudinal integrated rural placements: a social learning systems perspective. Med Educ 2013;47:352-61.

30 Brown ME, Anderson K, Finn GM. A narrative literature review considering the development and implementation of longitudinal integrated clerkships, including a practical guide for application. J Med Educ Curric Dev 2019;6:238212051984940.

31 Burgess A, Bleasel J, Haq I, et al. Team-based learning (TBL) in the medical curriculum: better than PBL? BMC Med Educ 2017;17:243

32 Wiener $\mathrm{H}$, Plass $\mathrm{H}$, Marz R. Team-based learning in intensive course format for firstyear medical students. Croat Med J 2009;50:69-76

33 Mak DB, Miflin B. Clinical audit in the final year of undergraduate medical education: towards better care of future generations. Med Teach 2012;34:e251-7.

34 Lawson McLean A, Saunders C, Velu PP, et al. Twelve tips for teachers to encourage student engagement in academic medicine. Med Teach 2013;35:549-54.

35 Soriano RP, Blatt B, Coplit L, et al. Teaching medical students how to teach: a national survey of students-as-teachers programs in U.S. medical schools. Acad Med 2010;85:1725-31.

36 GMC. Good medical practice, 2013. 